\title{
Cuidado de sí y cuidado del otro. Aportes desde M. Foucault para pensar relaciones entre subjetividad y educación
}

\section{Care of self and the other. M. Foucault contribution to think over relationships between subjectiveness and education}

\section{SILVANA P. VIGNALE}

Consejo Nacional de Investigaciones Científicas y Técnicas (CONICET) / Universidad del Aconcagua (UDA) / UNLA (Universidad Nacional de Lanús). Mendoza, (Argentina).

Recibido: 18-02-2011 Aprobado definitivamente: 25-03-2011

\section{RESUMEN}

La cuestión del «conocimiento de sí» como opuesto a la «experiencia de sí mismo»aparece problematizada en las primeras clases de La hermenéutica del sujeto. El estudio de Foucault sobre la experiencia de sí es realizado a partir del análisis de prácticas antiguas, que se traducen en «ocuparse de sí» y «cuidar de sí mismo». Nos interesa a partir de estas lecturas trabajar la dimensión ético-política del cuidado de sí, en su vínculo con el cuidado del otro. La pregunta que hacemos en una lectura desde el presente es ¿por qué educar? ¿Por qué insistir en la educación?

\section{PALABRAS CLAVES}

CONSTITUCIÓN DEL SUJETO, CUIDADO DE SÍ Y CUIDADO DEL OTRO, EDUCACIÓN, PEDAGOGÍA, PSICAGOGIA, PARRHESIA

\footnotetext{
CC Contrastes. Revista Internacional de Filosofía, vol. XVII (2012), pp. 307-324. ISSN: 1136-4076 Departamento de Filosofía, Universidad de Málaga, Facultad de Filosofía y Letras Campus de Teatinos, E-29071 Málaga (España)
} 


\begin{abstract}
The issue of «self knowledge» in opposition to the «experience of the self» appears as a problem in the first classes of The Hermeneutics of the Subject. Foucault's study on the experience of the self is made on the basis of the analysis of antique practices which can be translated into «taking care of oneself» and «caring about oneself». Based on these lessons, our interest is to work on the ethical-political dimension of the caring about oneself, on its link with caring about others. The questions we ask from a present analysis are: Why do we have to educate? Why do we have to insist on education?
\end{abstract}

KEY WORDS

CONSTITUTION OF THE SUBJECT, CARE ABOUT THE SELF AND THE OTHERS, EDUCATION, PEDAGOGY, PSICAGOGIA, PARRHESIA

\title{
I. LA «INQUIETUD DE SÍ» EN EL MARCO DE UNA ESTÉTICA DE LA EXISTENCIA
}

LUEGO DE COMPRENDER LA INFLUENCIA NIETZSCHEANA en el momento genealógico de las investigaciones de Foucault, en cuanto a lo metodológico y al análisis del poder en término de luchas de fuerzas, arribamos a una nueva etapa de su trabajo. En ésta, el sujeto aparece constituyéndose a sí mismo a partir de las propias prácticas y técnicas que ejerce sobre sí. La frase de Píndaro, que subtituló al Ecce Homo de Nietzsche parece ser el epígrafe de los estudios de Foucault en esta etapa: «cómo se llega a ser el que se es». La influencia de Nietzsche es aquí también insoslayable si consideramos que el superhombre es aquél que puede darse su propia ley y crear sus propios valores, «crearse a sí mismo», mediante una máxima de eterno retorno que le interpelaría a cuestionarse, cada vez, por la consecución entre sus pensamientos y sus acciones, para no caer en la mediocridad.

Aunque este desvío hacia textos de la Antigüedad Clásica no tiene por fin decir que hay que retornar a los griegos y romanos, o reelaborar una ética al modo de aquellos, la pregunta de por qué Foucault se vuelve hacia ellos, luego de sus estudios genealógicos, no deja de generar cierta inquietud. Hipotéticamente podemos pensar que tratara de ver los modos en que el sujeto se constituyó a sí mismo en diferentes momentos históricos, que le permitirían formular una historia de la filosofía como historia de las prácticas de veridicción, y orientarse hacia una ontología de nosotros mismos, tal como lo señalara el curso de 1983, El Gobierno de sí y de los otros (Foucault 2009). De este modo, se desplaza una historia «ideal» del pensamiento hacia una historia de los acontecimientos en el pensamiento occidental, y con ello las formas de subjetivación pueden analizarse a partir de las prácticas, y no del conocimiento de sí mismo, como 
instancia de reflexión sobre una supuesta interioridad. La noción de inquietud de sí constituye, para Foucault, uno de los acontecimientos en el pensamiento, como lo será la noción de parrhesia.

Foucault concibe la inquietud de sí mismo como una actitud general, una manera determinada de atención, de mirada sobre lo que se piensa y lo que sucede en el pensamiento. ${ }^{1}$ Implica también acciones que uno ejerce sobre sí, mediante las cuales se hace cargo de sí mismo, se modifica, se purifica, se transforma y transfigura. En síntesis, es una actitud con respecto de sí mismo, con respecto a los otros, y con respecto al mundo (Foucault 2001, p. 28). Por este motivo, esta noción es importante como acontecimiento del pensamiento, no sólo en cuanto define una forma de reflexión, que puede insertarse en una historia de las ideas, sino en cuanto concierne a la historia misma de la subjetividad, o en palabras de Foucault, en la historia de las prácticas de la subjetividad.

El ocuparse de sí tiene como ancestro en la Grecia arcaica una serie de prácticas que Foucault reúne bajo el nombre de «técnicas de sí» o «tecnologías de sí» (o «del yo»). Por éstas entiende «prácticas meditadas y voluntarias mediante las cuales los hombres no sólo fijan reglas de conducta, sino que procuran transformarse a sí mismos, modificarse en su ser singular y hacer de su vida una obra». ${ }^{2}$ Foucault tiene la hipótesis de que a partir de Sócrates y Platón se produjo una reorganización de estas técnicas de sí. Y que en el pensamiento filosófico, la cuestión de la inquietud de sí retoma, en un nivel y con un fin muy distinto, y con formas parciales diferentes, elementos que podían encontrarse en esas técnicas (como serán entre los estoicos el ejercicio de la retirada de sí, las técnicas de concentración del alma, la práctica de purificación, ente otras).

El precepto griego del famoso oráculo de Delfos «conócete a ti mismo» estaba en la Antigüedad Clásica ligado al precepto de la inquietud de sí. Por aquél no se entendía, como luego, una búsqueda en la interioridad o reflexión sobre sí mismo; la fórmula no era el autoconocimiento como fundamento moral o religioso. Era un precepto práctico de atención a uno mismo, y por eso se asocia con el cuidado u ocupación de sí, que tiene como fin la transformación del sujeto.

Las cuestiones «¿cómo tener acceso a la verdad?» y «icuáles son las transformaciones necesarias en el ser mismo del sujeto para tener acceso a la verdad?» se encontraban vinculadas en la Antigüedad. Filosofía y espiritualidad, de algún modo, iban juntas.

1 A lo largo de este trabajo usaremos indistintamente, como Foucault, los términos «inquietud de sí», «cuidado de sí», «ocuparse de sí» o «preocuparse de sí» para la traducción de epimeleia heautou o cura sui.

2 Cfr. Foucault, Dits et Écrits IV, num. 338: 545, citado en Foucault 2001: 59 por F. Gross, en la nota de edición 5. 
Llamemos «filosofía» la forma de pensamiento que se interroga acerca de lo que permite al sujeto tener acceso a la verdad, la forma de pensamiento que intenta determinar las condiciones y los límites del acceso del sujeto a la verdad. Pues bien, si llamamos «filosofía» a eso, creo que podríamos llamar «espiritualidad» la búsqueda, la práctica, la experiencia por las cuales el sujeto efectúa en sí mismo las transformaciones necesarias para tener acceso a la verdad. (Ibid., p. 33).

Luego, en la historia del pensamiento occidental la noción de inquietud de sí fue desplazada o reabsorbida por la noción délfica del conócete a ti mismo. El encubrimiento de la inquietud de sí por el conócete a ti mismo obedece a las modificaciones en las relaciones entre sujeto y verdad, que partir del «momento cartesiano» y de acuerdo al modo en que el pensamiento rehizo su propia historia, situó el punto de partida en la evidencia del cogito. Descartes con su célebre frase «cogito ergo sum» («pienso, luego existo»), señaló el autoconocimiento como principio de evidencia de lo real. La indubitabilidad de la existencia como sujeto se vuelve el acceso fundamental a la verdad. Las cosas pueden conocerse en la medida en que el yo se conoce a sí mismo. Ahora bien, Foucault señala que el momento en que cambia el rumbo de estos preceptos puede remontarse a Platón, como lo demostrará en su lectura de Alcibíades.

La escisión entre el conocimiento de sí y la inquietud de sí tiene como consecuencia, para la historia del pensamiento y de la subjetividad, que el sujeto ya no tiene que transformarse para ser poseedor de la verdad; es la ruptura entre el acceso a la verdad y la exigencia de una transformación del sujeto. Sin embargo, Foucault muestra que en la historia de la filosofía esta cuestión no desapareció del todo, y que en el caso del marxismo o en el psicoanálisis están en el corazón mismo de sus reflexiones.

La sospecha de Marx, Nietzsche y Freud se situará sobre el armazón que el «conócete a ti mismo» se construyó a lo largo de varios siglos. El descubrimiento del inconciente es de gran importancia por el papel epistemológico que juega en las llamadas «ciencias del hombre», ya que señala un principio de la anunciada muerte del hombre, es decir, la desaparición del hombre como fundamento y la desaparición de la identificación de la conciencia con la representación. Foucault es heredero de esa sospecha. La filosofía del sujeto había mostrado la identificación entre el sujeto y la interioridad o reflexión. Al enunciar la problemática de la subjetividad en términos de dispositivos de saber, de poder y de tecnologías del yo, Foucault pone de relieve una subjetividad que no es del orden de lo originario, sino del orden de la producción. Y la propuesta de realizar una historia de los acontecimientos en el pensamiento permite pensar una historia de la subjetividad deconstructiva del sujeto como fundamento. 


\section{LA CUESTIÓN DEL CUIDADO DE SÍ Y DEL OTRO EN EL MOMENTO PLATÓNICO Y EN EL MOMENTO HELENÍSTICO ROMANO}

Nos ocuparemos ahora de algunos puntos de inflexión de La hermenéutica del sujeto, que nos interesan a los fines de este trabajo. Foucault analiza allí dos momentos, el momento socrático-platónico, a partir del diálogo de Alcibíades de Platón; y en segundo lugar, el período de la edad de oro de la cultura de sí, los dos primeros siglos de nuestra era, o también llamado período helenístico romano, a partir de textos de varios autores, entre ellos Epicuro, Séneca, Marco Aurelio y Epicteto.

Habíamos dicho que la inquietud de sí mismo era una actitud no sólo con respecto a sí mismo, sino también con respecto a los otros. Podemos anticipar entonces que este principio, ligado a la espiritualidad de la Antigüedad, no concierne al sujeto aislado. Ahora bien ¿por qué en el principio de ocuparse de sí mismo es fundamental no sólo lo que concierne a la singularidad de la subjetividad, sino también lo que concierne a los otros? ¿Y en qué medida podemos decir, o no decir, que la relación entre el ocuparse de sí y el ocuparse de los otros se trata de una relación pedagógica en los análisis foucaulteanos? Presentaremos, de modo sintético, cómo es analizado el cuidado de sí y del otro; el papel del otro en la formación del sujeto, ya sea como maestro, guía espiritual o amigo; y las diferencias entre esa guía espiritual y la pedagogía, si las hubiera.

\section{II.I EL MOMENTO PLATÓNICO}

En el primer momento, la inquietud de sí mismo nace en el texto platónico a partir del interés de Alcibíades de gobernar a los otros, como acción política definida. Para ello, éste tiene que transformar el privilegio estatuario que tiene en el gobierno sobre los otros.

Para esto, Alcibíades debe enfrentar a dos tipos de rivales, según le señala Sócrates. Los que también quieren gobernar su ciudad y los enemigos de la ciudad que han recibido mejor educación que él (en referencia a persas y espartanos). A diferencia de ellos, Alcibíades no recibió buena educación, en dos aspectos. En cuanto a lo pedagógico -fue educado por un esclavo ignorante-, y en cuanto a las relaciones de eros que se mantenían entre adultos y jóvenes guías y a la vez amantes de éstos. La crítica del amor es presentada en el diálogo a razón de que Alcibíades, como otros, era buscado por su cuerpo, y abandonado en la edad crítica en que los jóvenes tienen que dar el paso hacia la vida política, formarse para su ejercicio. Los adultos, al buscar al joven sólo por el esplendor de su belleza, no se ocupaban de él, por lo tanto, no podían incitarlo a ocuparse de sí mismo. Esta es la doble falta de la pedagogía de ocuparse de sí. Ante esta situación, Sócrates, como maestro de Alcibíades, le recomienda conocerse a sí mismo, y es éste un consejo de prudencia: «mira cómo eres en 
relación a aquellos que quieres enfrentar». Le aconseja para poder ocuparse de los otros, antes, ocuparse de sí mismo.

Tenemos entonces, como primera característica de la inquietud de sí en este análisis, que la necesidad de preocuparse por sí mismo está ligada a una cuestión política, al ejercicio del poder. No es posible gobernar a los otros, si uno no se gobierna a sí mismo, no es posible transformar los propios privilegios en acción política sobre los otros, si no se ha preocupado por sí mismo. Además de este aspecto vinculado al poder, en segundo lugar, encontramos que en la necesidad de ocuparse de sí mismo se halla una insuficiencia en la educación de Alcibíades. Por lo tanto, la necesidad de la inquietud de sí se inscribe no sólo dentro de un proyecto político sino dentro del déficit pedagógico. Según el texto de Platón, además, esta ocupación de sí debe darse en el momento en que se sale de la mano de los pedagogos y se entra en el período de la actividad política. Y en tanto actividad y necesidad de los jóvenes, la inquietud de sí aparece en una relación entre aquellos y un maestro, o entre ellos y su amante. Por tanto, podemos anticipar, como tercera característica, que la actividad de ocuparse de sí tiene como punto importante la relación con otro: otro que se convierte en el maestro, o maestro/amante.

Ahora bien, Sócrates le aconseja a Alcibíades ocuparse de sí mismo, para luego ocuparse de los otros. Foucault llama la atención sobre algo que sucede en el diálogo entre maestro y discípulo, que nos interesa especialmente en la relación entre la formación y la constitución de la subjetividad. Ante la cuestión de que Alcibíades ignora (ignorancia que es, a la vez, ignorancia de las cosas que habría que saber para gobernar a los otros e ignorancia de sí mismo), Sócrates no da como respuesta la consecuencia esperada: «tienes que aprender». Lo que le aconseja es ocuparse de sí. Se produce así un desfasaje entre el «aprender», o la pedagogía entendida como aprendizaje, y el imperativo «ocuparse de sí», como otra forma de cultura, como paideia, que gira en torno a la cultura de sî o a la formación de sí. Es en este momento en que Sócrates se pregunta ¿qué es ocuparse de sí mismo? La respuesta debe dar, en el contexto de la pregunta -el ocuparse de sí de Alcibíades- un saber para gobernar a los demás. Pero se advierte que la pregunta es doble, por un lado se cuestiona ¿qué es ese sí mismo del que hay que ocuparse? Y en segundo lugar en relación a la inquietud ¿en qué debe consistir esa ocupación, esa inquietud?

Nos ocuparemos aquí de la primera interrogación, ¿qué es el sí mismo? ${ }^{3}$

3 La segunda interrogación, «¿qué es ocuparse de sí mismo?» será respondida con el precepto «conócete a ti mismo», mencionado aquí por tercera vez en el diálogo. Conocerse a sî mismo será posible si miramos en el elemento divino, y nos reconocemos. Conocerse, conocer lo divino, reconocer lo divino en uno mismo: eso es lo fundamental en la forma platónica de la inquietud de sí. 
Foucault señala que es una «Pregunta, por consiguiente, que no se refiere a la naturaleza del hombre, sino a lo que hoy llamaríamos - porque la palabra no figura en el texto griego- la cuestión del sujeto» (Ibid., p. 53). Sócrates responde con la inscripción del oráculo délfico, «conócete a ti mismo». Pero este conocerse no es de ninguna manera un saber acerca de la naturaleza humana, de las capacidades propias o de las pasiones del alma; Foucault lo explica como una sugerencia metodológica y formal. Saber qué es ese sí mismo del cual hay que ocuparse es traducible a esta nueva pregunta:

¿[Cuál es] esa relación, qué es lo que se designa mediante ese pronombre reflexivo heauton, qué es ese elemento que es igual del lado del sujeto y del lado del objeto? Tienes que ocuparte de ti mismo: eres tú quien se ocupa; y además, te ocupas de algo que es lo mismo que tú, [lo mismo] que el sujeto que «se ocupa de», tú mismo como objeto. (Ibid., p. 66).

La respuesta es la que Platón acostumbra a dar en sus diálogos: uno debe ocuparse de su alma. Pero aquí Foucault muestra que en el texto de Alcibíades el alma no es, como en otros diálogos, definida como prisionera del cuerpo (en Fedón), ni tampoco como la yunta alada (en Fedro), ni una arquitectura que armonizar (en La República). Es el alma únicamente en cuanto es sujeto de la acción. Se trata de la posición singular y trascendente del sujeto respecto a lo que lo rodea, a los objetos que tiene a su disposición, pero también a los otros con los cuales está en relación, y por último, respecto a sí mismo. «Lo que descubre [Platón] no es en absoluto el alma sustancia: es el alma sujeto» (Ibid., p.71).

Es en este punto del texto donde Foucault señala que en la inquietud de sí siempre se requiere de la relación con algún otro que es el maestro. «Uno no puede preocuparse por sí mismo sin pasar por el maestro, no hay inquietud de sí sin la presencia de un maestro» (Ibid., p.72). Y esta relación se define porque el maestro se preocupa de la inquietud de aquél a quien guía. El objeto de sus desvelos no es el cuerpo, ni los bienes del amado, a diferencia del médico y del padre de familia. Foucault muestra que desde este momento en que debe referirse al alma en cuanto sujeto, la inquietud de sí va a poder distinguirse de tres actividades: la del médico, la del dueño de casa y la del enamorado. El primero en cuanto no se ocupa del sí mismo, sino del cuerpo. En segundo lugar, ocuparse de los bienes propios no es ocuparse de sí mismo. En tercer lugar, los pretendientes de Alcibíades no se ocupan del sí mismo, sino de la belleza del cuerpo.

Nos interesa aquí señalar la diferencia que se establece entre profesor y maestro, que nos permite pensar a la inquietud de sí como algo diferente al aprendizaje o a la educación, algo que a partir de ese déficit que deja la pedagogía, se hace necesario tener en cuenta, ejercer, ocuparse, a partir de cierta 
edad, en que el joven debe insertarse en la vida política, de acuerdo al texto platónico. Dice Foucault:

A diferencia del profesor, no se preocupa por enseñar aptitudes o capacidades a aquel a quien guía, no procura enseñarle a hablar, no trata de enseñarle a imponerse a los demás, etc. El maestro es quien se preocupa por la inquietud que el sujeto tiene con respecto a sí mismo y quien encuentra, en el amor que siente por su discípulo, la posibilidad de preocuparse por la preocupación de éste en relación consigo mismo. Al amar de manera desinteresada al joven, se erige, por lo tanto, en el principio y el modelo de la inquietud que éste debe tener por sí mismo en cuanto sujeto. (ibid., p. 73).

Sócrates esperó que Alcibíades fuera mayor para dirigirle la palabra, esto da muestras de que él se ha preocupado por el propio Alcibíades, por su alma-sujeto de acción. Se ha preocupado por la manera en que Alcibíades va a preocuparse de sí mismo. Un profesor sólo puede enseñar a su discípulo capacidades, aptitudes. Pero no hace que se relacione consigo mismo. Esta tarea será del maestro. Y será posible en la relación de preocupación y de amor: el maestro se preocupa por la preocupación de su discípulo, en razón del amor que siente por él. La relación entre ambos dará lugar a que el joven se ocupe de sí mismo. Analizaremos esta forma de relación entre guía y amor bajo la forma de la psicagogia, como aparece en algunos párrafos de El gobierno de sí y de los otros.

\section{II.2.1 PSICAGOGIA}

La psicagogia puede definirse como el gobierno del alma (Foucault 2009, p. 312). ${ }^{4}$ En Fedro el discurso sobre el amor de Sócrates muestra el lazo existente entre el acceso a la verdad y la relación del alma consigo misma. En ese camino a la verdad, es necesaria la relación con la propia alma o con el alma del otro a través del amor, una relación tal que pueda modificar esa alma y hacerla capaz de acceder a la verdad. Eso es la psicagogia: la relación con la verdad en el discurso, que no puede disociarse del efecto inmediato que genera, no sólo en el alma de aquel a quien se dirige el discurso, sino en la de quien lo pronuncia. Esta cuestión está asociada en El gobierno de sí y de los otros a la filosofía y la parrhesia. El filósofo no puede sino ser un parrhesiasta, de lo cual hablaremos más adelante.

También la noción de psicagogia aparece en El gobierno de sí y de los otros cuando Foucault quiere mostrar la relación de la filosofía con la acción sobre las almas, el gobierno de los otros, la dirección y conducción del otro.

4 Tomamos aquí para ampliar la noción de psicagogia que aparece en el curso de $L a$ hermenéutica del sujeto, lo referido a este concepto en El gobierno de sí y de los otros. 
La filosofía, entendida no sólo como logos, sino como ergon, como ejercicio o práctica. Ésta es definida en el marco de los análisis foucaulteanos de la Carta VII de esta manera:

Si es cierto que la filosofía no es simplemente el aprendizaje de un conocimiento, y también debe ser, en cambio, un modo de vida, una manera de ser, cierta relación práctica consigo mismo mediante la cual uno se forja y trabaja sobre sí, si es cierto que la filosofía debe, pues, ser askesis (ascesis), el filósofo, cuando tiene que abordar no sólo el problema de sí mismo sino el de la ciudad, no puede conformarse con ser logos y nada más, ser el que dice la verdad, sino que debe ser alguien que participa, que pone manos a la obra en el ergon. (Ibid., pp. 230-231)

Destacamos este párrafo en primer lugar, para mostrar que la filosofía es entendida también como una de aquellas técnicas de sí, que tienen como fin la transformación del sujeto, en su relación con la verdad. Más adelante Foucault señalará también, a través del análisis de Platón, que la filosofía no puede ser enseñada a través de un material escrito, sino a través de una synousia, un ser con, una conjunción, un cohabitar en ella (Ibid., p. 256). En segundo lugar, para mostrar la importancia de una filosofía como psicagogia: la filosofía como práctica o ejercicio de sí consigo para la dirección del alma y la transformación del sujeto. La filosofía no puede ser enseñada, sino ejercida, y esta cuestión tiene su paralelismo con lo que arriba mencionábamos de la distinción entre el profesor y el maestro. No hay una capacidad que un profesor pueda enseñar para hacer filosofía, sino sólo la preocupación del maestro por la preocupación de sí mismo de su discípulo.

Esta relación de psicagogia es descripta más adelante en relación a una filosofía parresiástica, que en su actividad psicagógica, se dirige «al discípulo, a la otra alma, a aquel a quien se busca y cuya alma, y eventualmente el cuerpo, también se busca [...]. Es cierta relación de inclusión, de reciprocidad, cierta relación de acoplamiento, una relación que es pedagógica y erótica» (Ibid., pp. 357-358).

En esa relación con el otro, es de gran importancia la relación con la verdad. El discurso del otro no se da como la retórica en el terreno agonístico, y en cuyo uso se impone el discurso sobre otros y los reúne bajo esa unidad de mando, sino que «es un juego de prueba de a dos, por afinidad de naturaleza y manifestación de la autenticidad, de la realidad-verdad del alma» (Ibid., p. 375). El criterio de verdad de un discurso filosófico no puede buscarse en una suerte de vínculo interno entre quien piensa y la cosa pensada. La verdad del discurso no se alcanza de ninguna manera en la forma de lo que más adelante será la evidencia, sino por algo que se llama homología, es decir la identidad del discurso entre dos personas. Y para que esa homología sea una prueba de la calidad del alma, se requieren tres criterios: episteme, un saber que no es un 
conocimiento ya aprendido, sino más bien el hecho de que nunca se dice lo que se dice sino en virtud de saber que es efectivamente verdad; segundo, eunoia, o amistad; y en tercer lugar, parrhesia, o coraje de decir lo que se piensa. Este discurso, el que reúne estos tres elementos, tiene la capacidad de efectuar la psicagogia. Mediante esta concepción «de la homología y de su condición interna que culmina en la parrhesía, tenemos la definición del vínculo mediante el cual el logos de uno puede actuar sobre el alma del otro y conducirlo a la verdad» (Ibid., p. 378). La parrhesia, como veremos más adelante, liga uno a otro el maestro y el discípulo, y la parrhesía filosófica no conduce a una retórica sino a una erótica.

\section{II.3. MOMENTO HELENÍSTICO ROMANO}

En Sócrates y Platón la inquietud de sí está ligada directamente a la cuestión de la pedagogía. Como la pedagogía es insuficiente, es necesario ocuparse de sî mismo, para preparar al joven en el ejercicio del poder, bajo la forma fundamental del autoconocimiento. En el análisis de los primeros dos siglos de nuestra era, Foucault muestra un desplazamiento de la inquietud de sí en relación a la pedagogía. En el período grecorromano, hay que ocuparse de sí mismo no cuando uno es joven, sino en todas las circunstancias, porque la pedagogía, cualquiera sea, es incapaz de garantizarlo. Ocuparse de sí será una ocupación durante toda la vida, y tendrá como edad crucial ya no la adolescencia, sino la madurez. Puesto que ya no será la preparación para la vida adulta y cívica, sino para la vejez. «Para preparar el cumplimiento de la vida en esa edad en la que la vida misma se cumplirá y quedará como suspendida, y que será la vejez» (Foucault 2009, pp. 85-86). No debe considerarse la vejez simplemente como término de la vida, sino como una meta. El anciano es quien goza de sí mismo, y el punto al que llega en la vejez, si ha sido bien preparada por una larga práctica de sí, es el punto en que el yo se alcanza por fin a sí mismo, donde se reúne consigo y mantiene una relación consumada consigo mismo.

En este momento la inquietud de sí se convierte en un «arte de vivir» (tekhne tou biou), extendido para todos los individuos y no exclusivamente para los jóvenes aristocráticos, y ya no tiene como objetivo el gobierno de la ciudad. La meta ahora es el sí mismo: «hay que ir hacia el yo como se va hacia una meta» (Ibid., p. 213). Foucault llama a este proceso prolongado y continuo a lo largo de la vida autosubjetivación, para distinguirlo de lo que posteriormente será la conversión cristiana (que tiene como objetivo la renuncia de sí mismo mediante una cesura o ruptura esencial en el sujeto). La inquietud de sí, a diferencia del momento platónico, no tendrá la sola forma del autoconocimiento, sino a un conjunto más vasto de prácticas. Estas prácticas prepararán al sujeto no para su profesión o rol social, sino para los acontecimientos de la vida. Para ello, el 
sujeto se armará de un «equipamiento» (a través de discursos y prácticas) que le ayudará a sobrellevarlos.

La idea de educación aparece en esta forma de la edad de oro grecorromana de la inquietud de sí, pero como una educación generalizada: la vida en su totalidad debe ser educación del individuo. Uno va a educarse a sí mismo a través de todas las pruebas y acontecimientos de la vida. Foucault señala el carácter «etopoiético» del saber, es decir, se trata de un saber cuya característica es introducir como efecto una modificación en el modo de actuar y de ser. Entre los cínicos y epicúreos este saber tiene por fin que la verdad (el saber de las cosas, los dioses, los hombres, como conocimiento relacional) afecte al sujeto, y lo transforme. Los ejercicios y técnicas de sí mismo deben provocar una discontinuidad en lo que se es.

Además, la inquietud de sí conlleva una función crítica, y tiene un papel corrector en la misma medida que formativo. Foucault señala que la noción de desaprendizaje es crucial para los cínicos, y también para los estoicos. En especial se trata de una crítica a la primera infancia y a las condiciones en que se desenvuelve. Por consiguiente, la inquietud de sí, debe invertir por completo el sistema de valores vehiculizados e impuestos por la familia, pero también se trata de una crítica a la formación pedagógica, la de los maestros y sobre todo, los profesores de retórica. Más adelante nos referiremos a este punto. Quisiéramos dirigirnos ahora sobre el asunto que nos interesa, que es la cuestión del otro en el desplazamiento de la inquietud de sí en los siglos I y II.

Habíamos dicho que la primera característica de la práctica de sí en este periodo es su integración con el arte de vivir. En segundo lugar, es aplicable a todos, sin ninguna condición previa de estatus o finalidad técnica, profesional o social. Es importante comprender que la idea de «salvación» es central en todo esto. Pero para ello Foucault plantea un problema previo, que es la cuestión del otro, de la relación con el otro. «Para que la práctica de sí llegue a ese yo al que apunta, es indispensable el otro» (Ibid., p. 131). ¿Por qué?

En el momento platónico, la importancia del otro se mostraba a partir de la presencia de estos maestros-amantes, cuya sola cercanía era prestigiosa por el ejemplo que pudieran ser. Por otro lado, los rivales, con quienes se competía por el mismo fin. Y por último, el magisterio socrático, que intenta mostrar que ignora que sabe, entonces su papel es trasmitirle el saber mediante la muestra de que en realidad sabe lo que no sabe. En todos los casos se trata de la ignorancia y de la memoria, del un sujeto que tiende a un saber que sustituye su ignorancia, el pasaje de la ignorancia al saber.

En el periodo helenístico y romano, la necesidad del otro sigue siendo tan importante, y la cuestión de la ignorancia no deja de estar presente, aunque cobra mayor relieve el hecho de la «mala formación», en cuanto a hábitos, malas 
costumbres, falsas opiniones, malos maestros, de padres, el entorno. Por lo tanto, el sujeto no debe tender a un saber que sustituya su ignorancia, sino que tiene que sustituir el estatus de no-sujeto por el de sujeto, mediante la relación de sî consigo. Tiene que constituirse como sujeto, y en eso debe intervenir otro. El maestro ya no es el maestro de la memoria, sino un operador en la formación del individuo como sujeto, el mediador en la relación del individuo con su constitución de sujeto. Este «mediador» no debemos entenderlo como aquel que media entre el individuo y el conocimiento de las cosas, sino más bien como aquel tercero entre yo y mí mismo, que es el amigo (Nietzsche 1998, p. 96). El tema de la amistad como una de aquellas formas de relación mediante las cuales el sujeto se constituye a sí mismo, aparece tanto en estoicos como en epicúreos.

Ahora bien, cuando todavía no hemos cuidado de nosotros mismos estamos en estado de stultitia, un estado opuesto a la práctica de sí. Quien está en estado de stultitia es quien no se ha preocupado por sí mismo, quien está expuesto a todos los vientos, abierto al mundo externo, incapaz de hacer la discriminación entre las representaciones del mundo externo y los elementos subjetivos. Es quien está disperso en el tiempo, quien no se acuerda de nada, quien deja que su vida pase y no trata de llevarla a una unidad rememorando lo que merece recordarse. Es quien no es capaz de querer como es debido. Y el único objeto que puede quererse libremente es el yo. Y como en el estado de stultitia no se puede querer preocuparse por sí mismo, la inquietud de sí requiere de la presencia de otro.

Y ese otro, ese operador es el filósofo. El modo en que el filósofo se convierte en mediador para la constitución de sí es diferente a como puede serlo quien se dirige hacia otro en uso de la retórica. Mientras «la retórica es el inventario y el análisis de los medios para actuar sobre los demás a través del discurso», la filosofía «es el conjunto de principios y prácticas que uno puede tener a su disposición o poner a disposición de los otros, para cuidar como corresponde de uno mismo o de los demás» (Foucault 2001, p. 140). La filosofía tiene en este momento un marco institucional para llevar a cabo esta tarea de mediación en la constitución como sujetos de los individuos. En la forma helénica hay escuelas como la epicúrea, en que se tenía un director o guía con quien se entablaba una amistad y una ética de la palabra o parrhesía. En caso de los estoicos se trataba de grupos más cerrados en sí mismos que llevaban una existencia comunitaria. La forma romana, por su parte, es la del consejero privado. Pero también es importante que, al margen mismo de las instituciones o lugares institucionalizados para la filosofía, la práctica de sí se convierte en una práctica social.

Hubo, según Foucault toda una tendencia a desarrollar la práctica de sí al margen «de la profesión filosófica, y a hacer de ella un modo determinado de relación entre los individuos» (Ibid., p. 157), de modo que la figura del maestro se desdibuja. El amigo puede ser también aquél mediador entre yo y mí mismo. 
Ante un amigo con quien se tiene relaciones afectivas intensas uno puede hacer su examen de conciencia, que es una de las prácticas de sí más frecuentes en esta época, como lo es la correspondencia. La escritura de sí es una de las técnicas más interesantes en esa constitución del sujeto, y en muchos casos, esas anotaciones, reflexiones acerca de la vida, ese «equipamiento» del que uno se arma mediante los discursos que lee o escucha, son enviadas como cartas a un amigo. Hay dice Foucault «toda una práctica en que lectura, escritura, notas para sí mismo, correspondencia, envío de tratados, etcétera, constituyen toda una actividad del cuidado de sí y cuidado de los otros, de mucha importancia» (Ibid., p. 345). Lo escuchado o leído puede resultar de utilidad para cuando alguna situación de la vida lo reclame, para saber cómo actuar.

Con el desarrollo de la práctica de sí, se desarrolla una nueva ética, no tanto del lenguaje o del discurso en general, sino de la relación verbal con el otro. La parrhesia se convierte en una regla de juego.

\section{II.3.1 PARRHESIA}

La noción de parrhesia alude al decir veraz, al hablar claro, a la franqueza que hace que digamos lo que tenemos que decir. ${ }^{5}$ Está ligado a la actitud de quien habla y la coincidencia entre lo que dice y lo que es. Por eso se considera que siempre este decir veraz conlleva riesgos. Se trata de la adecuación entre el sujeto de la enunciación y el sujeto de la conducta, entre el sujeto que habla y dice la verdad, y el sujeto que se comporta como esa verdad lo quiere.

La parrhesia cuenta por esto con dos rivales, un rival moral, que es la adulación, y un rival técnico que es la retórica. El objetivo de la parrhesía es actuar de modo tal que el interpelado esté, en un momento dado, en una situación en la que ya no necesite el discurso del otro, porque ya lo ha interiorizado como verdad. «La parrhesia es, en cierto modo, la transmisión desnuda de la verdad misma, y asegura de la manera más directa la paradosis, el tránsito del discurso veraz de quien ya lo posee a quien debe recibirlo, quien debe impregnarse de él y poder utilizarlo y subjetivarlo» (Ibid., pp. 364-365). Se diferencia con la retórica, porque esta última es un arte que no se define por la relación personal o individual, por la situación táctica de quien habla, sino por el tópico que se aborda. La función esencial de la retórica es actuar sobre los otros, en el sentido en que se dirige o modifica las deliberaciones en asambleas, conduce el pueblo o un ejército. Actúa sobre los otros pero a beneficio de quien habla. La parrhesia tiene objetivos muy distintos. La posición de quien habla y quien escucha es muy diferente. También se trata de actuar sobre los otros, no tanto

5 El desarrollo aquí expuesto es a partir de La hermenéutica del sujeto. Una mayor dedicación a esta noción es encontrado en El gobierno de sí y de los otros a partir del análisis de tragedias griegas y de textos de Platón. 
para ordenarles algo, dirigirlos o inclinarlos por tal o cual cosa. Al actuar sobre ellos el propósito es que lleguen a constituir por sí mismos, con respecto a sí mismos, una relación consigo mismo.

La verdad de la parrhesia no es una verdad teórica, la verdad que tiene el maestro y debe transmitir al discípulo no es una verdad objetiva, sino subjetiva. Por ello es un «arte conjetural», opuesto a un «arte metódico», en el que se quiere llegar a una verdad segura gracias a una única vía. El arte conjetural procede por argumentos que son simplemente probables y plausibles «y por consiguiente, esto brinda a quien los utiliza la posibilidad de no seguir una regla - una regla única- e intentar, en cambio, alcanzar esa verdad probable mediante toda una serie de argumentos que se yuxtaponen, sin que sea necesario un orden necesario y único» (Ibid., p. 370). Por eso «lo que define esencialmente las reglas de la parrhesia es el kairos, la ocasión, que es exactamente la situación recíproca de los individuos y el momento que se escoge para decir esa verdad» (Ibid., p. 366).

El efecto de esa verdad del arte conjetural es la transformación del sujeto. Podríamos decir que se trata de una «política de la verdad». La parrhesia se convertirá en la práctica y el modo de relación de los discípulos entre sí, favorecerá la amistad entre ellos, si hubo una práctica de la palabra libre del maestro. Porque la parrhesia es como una especie de compromiso, una palabra que equivale a un lazo en cuanto el sujeto del discurso y el de la acción deben coincidir, no puede haber enseñanza de la verdad sin un exemplum. Por esto es necesaria la relación individual con el otro. Entonces aquí nuevamente Foucault hace una distinción entre pedagogía y psicagogia:

Llamemos «pedagógica», si quieren, la transmisión de una verdad que tiene la función de dotar a un sujeto cualquiera de aptitudes, capacidades, saberes, etcétera, que no poseía antes y que deberá poseer al término de esa relación pedagógica. $\mathrm{Si}$ llamamos «pedagógica», por lo tanto, la relación consistente en dotar a un sujeto cualquiera de una serie de aptitudes definidas de antemano, creo que se puede llamar «psicagógica» la transmisión de una verdad que no tiene la función de proveer a un sujeto cualquiera de aptitudes, etcétera, sino la de modificar el modo de ser de ese sujeto al cual nos dirigimos. (Ibid., p. 388)

\section{UNA ONTOLOGÍA DEL PRESENTE DE LA EDUCACIÓN}

A partir de los análisis aquí expuestos, nos interesa destacar algunos puntos del análisis foucaulteano de la inquietud de sí, que consideramos que pueden ser importantes para pensar la educación tal y como la concebimos en nuestro presente. 
En primer lugar, que no llegamos a ser quienes somos sino mediante las relaciones que establecemos. Para la constitución de sí mismo se requiere de otro: de la palabra y la escucha de otro y de la propia palabra y escucha en atención de otro.

En segundo lugar, el consejo de Sócrates para el discípulo que ignora: no «tienes que aprender» sino que «tienes que ocuparte de ti mismo».

En tercer lugar, y vinculado al anterior, una función crítica del cuidado de sí mismo, que nos conduce a «desaprender» lo aprendido. Como si en determinado momento, aquello que se aprendió transparentara que no es de las verdades que nos transforman, no sirviera para las «cosas importantes» o «para la vida», no formara parte de la constitución de la subjetividad, de la transformación que el sujeto debe darse a sí mismo para adquirir la verdad.

En cuarto lugar, una esfera diferenciada entre el profesor y el maestro. Para ocuparse de uno mismo, no se requiere de técnicas o verdades objetivas que un profesor pueda transmitir. Sino de la relación con uno mismo, que puede suscitarse mediante la preocupación del maestro en el cuidado de sí del discípulo. Por consiguiente, la diferencia entre retórica y filosofía y la importancia de la parrhesia como palabra de verdad.

Como vemos, varias cuestiones relativas a las relaciones entre sujeto y verdad están presentes en estos puntos. Pero no se trata aquí de una analítica de la verdad. Sino, por el contrario, de que el sujeto se constituye a sí mismo por su práctica de la verdad en relación con los otros; por tanto, podemos hablar de una «política de la verdad» en una «estética de la existencia». Recordemos las preguntas fundamentales del curso: «qqué precio debo pagar para tener acceso a la verdad?» Y como consecuencia «¿cuál es el trabajo que debo efectuar sobre mi mismo, que modificación debo realizar en mi ser para poder tener acceso a la verdad?».

Las relaciones entre el sujeto y la verdad, como lo ha señalado en varias oportunidades Foucault, han obedecido a dos modos de relación.

En primer lugar, una subjetivación del discurso de verdad, tal como lo hemos visto en aquello de «ir hacia el yo como se va hacia una meta». En este procedimiento de subjetivación, el discurso es apropiado por el sujeto como verdad, es decir, se hace propia una verdad. La verdad se vuelve un principio de acción y tiene como efecto la constitución de un sí mismo. Es una verdad para un sujeto.

En segundo lugar, una objetivación del discurso verdadero. A partir del momento cartesiano, la noción del conocimiento del objeto sustituye la de acceso a la verdad. El sujeto se vuelve un objeto de conocimiento y es producido por un saber-verdad (como podemos ver en educación claramente cuando se habla de un «sujeto educativo» o del «niño»). Por lo tanto, en la objetivación del discurso 
verdadero, el sujeto es apropiado por el discurso de verdad, el sujeto ya no se constituye a sí mismo, sino que es constituido o sustituido por el discurso de verdad. Es un sujeto para una verdad.

De acuerdo al modo en que se institucionaliza la educación (actualmente y desde sus orígenes), el modo de relación de la objetivación del discurso verdadero es también institucionalizado en las prácticas y relaciones entre profesores y alumnos. Podemos ver esto en el trabajo de Varela y Álvarez Uría, Arqueología de la escuela. Los autores realizan una genealogía de la escuela como institución de encierro, en cuya confianza se deposita gran parte de un programa político destinado a la cohesión social. La escuela fue creada bajo determinadas condiciones históricas e instrumentalizada bajo ciertos dispositivos. Los autores muestran los dispositivos y formas de ejercicio del poder mediante los cuales la educación adquiere su papel fundamental: naturalizar un determinado orden. La infancia forma parte de un programa político de dominación, de poderío y afianzamiento de las clases sociales altas. Para ello se hizo necesario que emerjan dispositivos institucionales y saberes especializados acerca de la infancia, capaces de lograr la formación y transformación de los niños y jóvenes: el espacio de encierro de la institución escolar y la formación de un cuerpo de especialistas.

En los trabajos correspondientes al momento genealógico de Foucault, en especial en Vigilar y castigar, hemos visto los medios del buen encauzamiento, y cómo, mediante la sanción normalizadora, el régimen de premios y castigos, la vigilancia permanente y el examen, la escuela misma es productora de subjetividades. El poder disciplinario tiene como función principal «enderezar conductas» (Foucault 2008, p. 199). Y la escuela funciona, sigue funcionando, a partir de un microsistema de penalidad, cuyo fin es que todos se asemejen.

Ahora bien, en sus últimas investigaciones, hemos visto cómo Foucault plantea la necesidad de encontrar formas de subjetivación, que no sean la sola sujeción del individuo al poder. La experiencia de sí mismo es el encuentro entre la sujeción al poder y la subjetivación que por medio de las técnicas de sí hace el sujeto sobre sí mismo. Tal vez debamos considerar este último punto para pensar la educación. Dentro del ámbito institucional de la escuela, encontrar las «fracturas» $\mathrm{o}$ «intersticios» para dar lugar a una relación singular de cada individuo con el saber.

Este trabajo ha presentado, a partir de cierta relación del sujeto y la verdad (transformadora del sujeto y constituyente de él) una liaison entre el ocuparse de sí mismo y el ocuparse de los otros, para pensar la educación. Si bien es cierto que Foucault no propone con estos estudios sobre la Grecia clásica y la época helenística y romana retornar a una ética de la antigüedad, sí encontramos en numerosos pasajes que estos estudios permiten una actualización de la noción 
del cuidado de sí en el pensamiento moderno, en tanto que algo pueda producirse en su contacto (Foucault 1999, p. 408). También elementos que a Foucault le permiten pensar la filosofía y la historia de la filosofía como parrhesía, como historia de las prácticas de veridicción (Foucault 2009, p. 355), como un ejercicio que transforma al sujeto en lo que piensa y en lo que es (Foucault 2003b, p.15). Del mismo modo, señala la necesidad y urgencia de una ética del yo, como resistencia al poder político, en la relación de sí consigo (Foucault 2001, p. 246). Por tanto, si bien Foucault no prescribe un retorno a una ética de la Antigüedad, sí encontramos que estos estudios sirven para encontrar elementos que permiten pensar nuestra realidad y presente, para una nueva ética del yo, «como tarea urgente, fundamental, políticamente indispensable» (Ibíd., p. 246). Él mismo señala como tarea realizar una «ontología del presente» $\mathrm{u}$ «ontología de nosotros mismos», como interrogación de nuestra propia actualidad en sentido filosófico, como interrogación de un «nosotros» del que formamos parte y respecto del cual tenemos que situarnos (Foucault 2009, p. 39).

Pensamos que hacer una ontología del presente de nuestra educación es ejercer esa función crítica de la filosofía que nos permite deslegitimar lo que ya sabemos, para saber hasta qué punto podemos pensar de otro modo. Desde este lugar, consideramos que las relaciones entre uno mismo y el otro, la parrhesia como modo de relacionarse con la verdad, las prácticas de constitución de sí que encontramos en La hermenéutica del sujeto, permiten pensar nuevamente las prácticas y las relaciones que hoy se tejen en eso que llamamos educación. Para una tal ontología del presente de la educación, necesitaremos de esa filosofía parresiástica, como coraje de decir lo que pensamos y en asunción de los riesgos que ello implique, para que cada uno pueda hacerse de su verdad y llegue a ser el que es.

\section{REFERENCIAS BIBLIOGRÁFICAS}

FOUCAULT, Michel. 2009. El Gobierno de sí y de los otros. Buenos Aires, Fondo de Cultura Económica.

-2003. El yo minimalista y otros ensayos. Buenos Aires, La marca.

_Estética, ética y hermenéutica. Barcelona, Paidós, 1999.

_2003b. Historia de la sexualidad; 2. El uso de los placeres. Buenos Aires, Siglo XXI.

— 2001. La hermenéutica del sujeto. Buenos Aires, Fondo de Cultura Económica. 2008. Vigilar y castigar; nacimiento de la prisión. Buenos Aires, Siglo XXI Editores Argentina.

NIETZSCHE, Friedrich. 1998. Así habló Zaratustra. Buenos Aires, Alianza.

VARELA Y ÁLVAREZ URÍA. 1991. La arqueología de la escuela. Madrid, La piqueta. 
SILVANA PAOLA VIGNALE es becaria del Consejo Nacional de Investigaciones Científicas y Técnicas (CONICET) y Profesora titular de Filosofía, de la carrera de Licenciatura en Psicología, Facultad de Psicología, Universidad del Aconcagua (UDA). Mendoza, Argentina.

\section{Líneas de investigación:}

Técnicas de subjetivación y prácticas de sí que se constituyen en estéticas de la existencia en la última fase de la obra de Michel Foucault.

\section{Publicaciones recientes:}

(2009) «Foucault, M. El gobierno de sí y de los otros». (reseña) Revista Estudios, Filosofía práctica e historia de las ideas. vol.11 n. 2. Mendoza, agosto/diciembre 2009. ISSN 1851-9490. http://www.scielo.org.ar/pdf/efphi/v11n2/v11n2a08.pdf

(2010) «Bíos, entre biopolítica y techne tou biou». Paralaje, Revista Electrónica de Filosofía. $\mathrm{N}^{\mathrm{0}}$ 5. 2010. Publicado en el dossier: «Biopolítica y amenaza: la seguridad sobre la vida». ISSN 0718-6770. http://paralaje.cl/index.php/paralaje/issue/view/12/showToc, y

Dirección electrónica: silvavignale@yahoo.com.ar 